\title{
New Pellet Injection Schemes on DIII-D*
}

\author{
S. K. Combs, L. R. Baylor, C. R. Foust, and T. C. Jernigan \\ Oak Ridge National Laboratory, P.O. Box 2009, Oak Ridge, TN 37831-8071 \\ P. M. Anderson and J. I. Robinson \\ General Atomics, P.O. Box 85608, San Diego, CA 92186-5608
}

\begin{abstract}
The pellet fueling system on DIII-D has been modified for injection of deuterium pellets from two vertical ports and two inner wall locations on the magnetic high-field side (HFS) of the tokamak. The HFS pellet injection technique was first employed on ASDEX-Upgrade with significant improvements reported in both pellet penetration and fueling efficiency. The new pellet injection schemes on DIII-D required the installation of new guide tubes. These lines are $\approx \mathbf{1 2 . 5} \mathrm{m}$ in total length and are made up of complex bends and turns ("roller coaster" like) to route pellets from the injector to the plasma, including sections inside the torus. The pellet speed at which intact pellets can survive through the curved guide tubes is limited $(\approx 200-300 \mathrm{~m} / \mathrm{s}$ for HFS injection schemes). Thus, one of the three gas guns on the injector was modified to provide pellets in a lower speed regime than the original guns (normal speed range $\approx 500$ to $1000 \mathrm{~m} / \mathrm{s}$ ).
\end{abstract}

The guide tube installations and gun modifications are described along with the injector operating parameters, and the latest test results are highlighted.

\section{INTRODUCTION}

The process and benefits of plasma fueling by the injection of frozen pellets of hydrogen isotopes into magnetically confined plasmas have been thoroughly documented in the literature (for example, [1] and [2]). In the high-field-side (HFS) pellet injection experiments on ASDEX-Upgrade [3], improvements in pellet penetration (factor of 2) and fueling efficiency (factor of 4) were obtained. These results were the motivation for the new injection schemes (Fig. 1) and experiments on DIII-D [4]. Straight guide tubes typically are used to transport

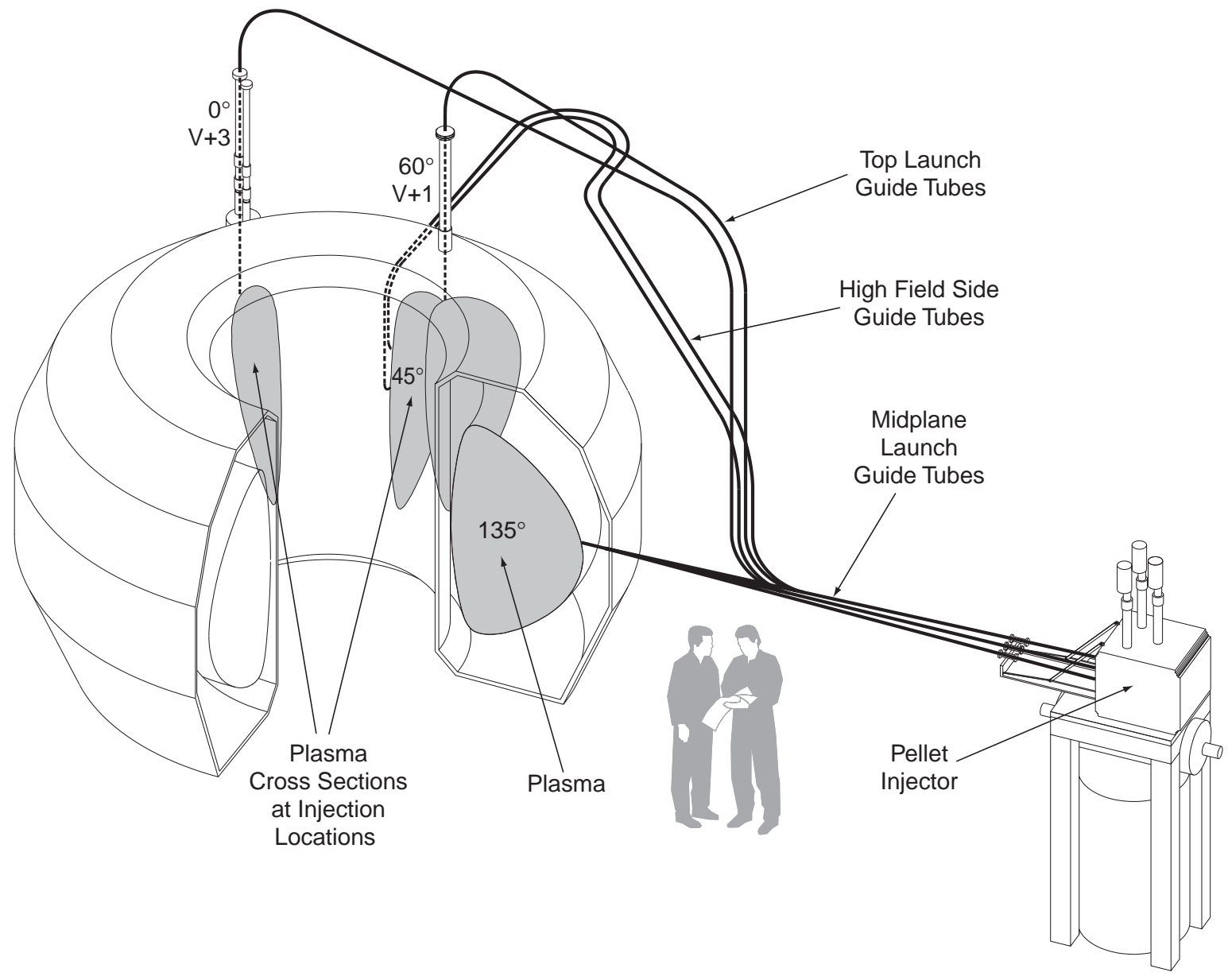

Fig. 1. DIII-D pellet injection system.

\footnotetext{
*Research sponsored by the Office of Fusion Energy Sciences, U.S. Department of Energy under contract DE-AC05-96OR22464, with Lockheed Martin Energy Research Corp.
} 
and deliver pellets from the output of the accelerator to the plasma; however, the new injection schemes dictate the use of curved guide tubes. The pellets are subjected to stresses from centrifugal and impact forces in the curved tubes, and the speed at which intact pellets can be delivered reliably to the plasma is limited. The generic development of curved guide tube technology [5,6] has been ongoing at the Oak Ridge National Laboratory (ORNL) for several years and provided the key design features/components for implementing the new injection schemes on DIII-D.

\section{DIII-D PELLET INJECTION SYSTEM}

While the injector used on ASDEX-Upgrade is a centrifuge [3], the DIII-D injector is a three-barrel pneumatic (light gas gun) injector [7-9]. With this injector, deuterium $\left(D_{2}\right)$ ice (or other solidified gas) is provided to the acceleration section by a cryogenic extruder, and pellets are formed/chambered with a punch mechanism and accelerated by gas in a gun barrel. Repetition rates of up to $10 \mathrm{~Hz}$ from a single gun have been attained. Detailed descriptions of the injector design and operations have been published [7-9]. The injector was originally used on the Joint European Torus from 1987 to 1991 for thousands of plasma shots (with 2.7-, 4.0-, and 6.0-mm pellets). It was then modified (two $2.7-\mathrm{mm}$ guns and one 1.8-mm gun), installed on DIII-D in 1994, and since has been used for standard outside launch or low-field side (LFS) injection in many DIII-D experiments. To date, more than 3500 pellets have been injected into DIII-D plasmas. While $\mathrm{D}_{2}$ is the pellet material for most experiments, operations with $\mathrm{H}_{2}, \mathrm{Ne}, \mathrm{Ar}, \mathrm{CH}_{4}$, and $\mathrm{D}_{2} / \mathrm{Ne}$ mixtures have also been carried out.

The pellet injection system on DIII-D is depicted in Fig. 1. The standard guide tubes are 7.9-mm ID by 12.7-mm OD. Three LFS guide tubes can deliver pellets $\approx 4 \mathrm{~m}$ to a common port $\left(135^{\circ}\right.$ relative toroidal position). For the new injection schemes, the guide tube lines are much longer $(\approx 12.5 \mathrm{~m})$. The hardware for top launch (or vertical pellet injection) was installed on DIII-D in 1998, with two guide tubes for delivering pellets through the $60^{\circ}(\mathrm{V}+1)$ and $0^{\circ}(\mathrm{V}+3)$ ports. The vertical guide tube through the $60^{\circ}(\mathrm{V}+1)$ port is aimed at a point inside the magnetic axis, and the $0^{\circ}(\mathrm{V}+3)$ guide tube is focused outside the magnetic axis. This year, the DIII-D pellet injection system and torus were equipped with the components for injection from two HFS inner wall locations $\left(45^{\circ}\right.$ relative toroidal position). The two inner wall tube installations are shown in more detail in Fig. 2 and are designated upper and lower HFS tubes. Both tubes are aimed at a point with a major radius of $160 \mathrm{~cm}$, with the lower tube closer to the machine horizontal midplane. For HFS pellet injection, the $1.8-\mathrm{mm}$ gun was modified to accommodate $2.7-\mathrm{mm}$ pellets. Thus, all three guns are now the same size. Two other modifications were made to the HFS gun; a new punch feature and an oversized gun barrel were added. With the new punch mechanism, the pellet is formed/chambered in the standard fashion, and then the subsequent action of a pusher rod initiates pellet motion before the propellant gas can cause "breakaway." This feature along with the oversized gun barrel allows reliable operation at lower pellet speeds $(\approx 100$ to $300 \mathrm{~m} / \mathrm{s})$ than the standard guns (speeds $\approx 500$ to $1000 \mathrm{~m} / \mathrm{s}$ ). These lower speeds are required for reliable delivery of intact pellets through the

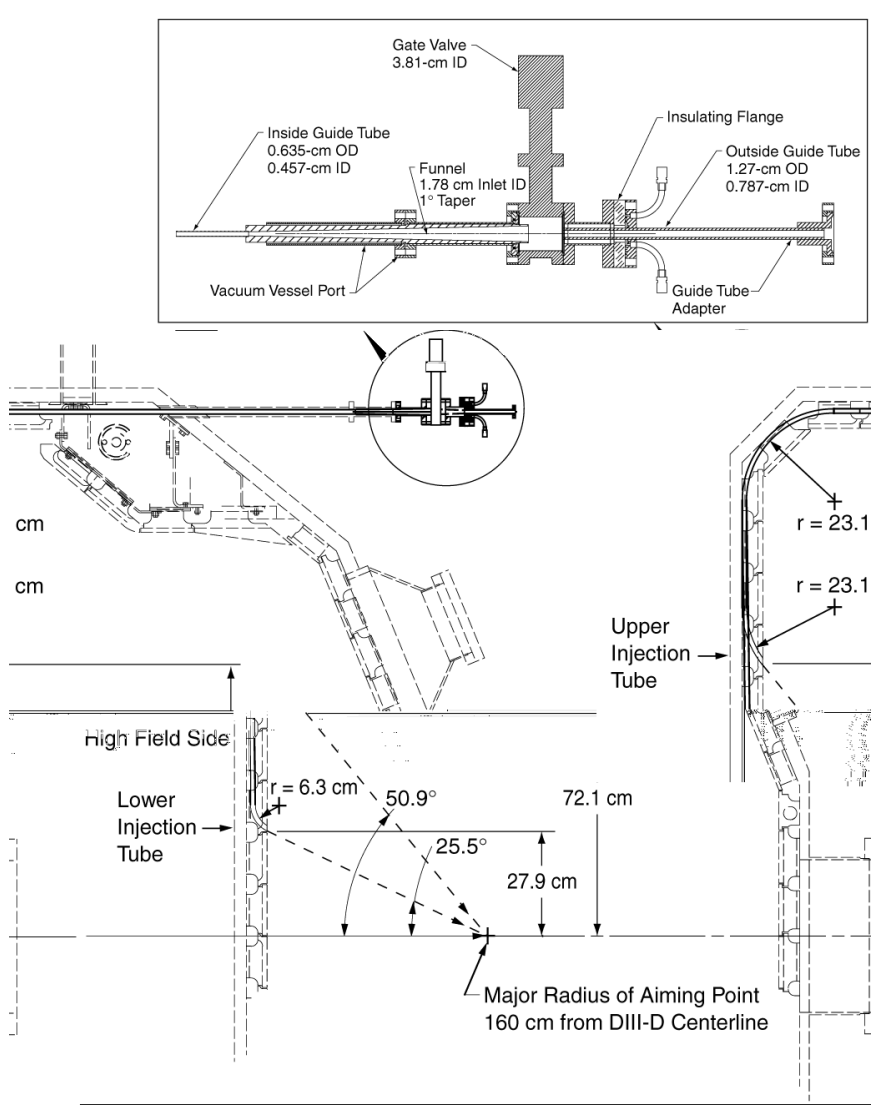

Fig. 2. HFS pellet injection tubes on DIII-D.

inner wall HFS tubes, as determined in simulation tests at ORNL and discussed in the next section.

A special union for attaching multiple tube sections was designed, fabricated, and successfully tested at ORNL. Each vertical and HFS tube installation includes two or three unions. Also, at the machine/HFS guide tube interfaces, funnels were incorporated at the downstream side of the electrical break (Fig. 2). The funnel inlet is large enough (17.8-mm ID) to ensure that all pellets are captured, and it transitions $\left(\approx 1^{\circ}\right.$ taper $)$ to the inside guide tube size $(4.57-\mathrm{mm}$ ID). These components were tested in the laboratory simulations described in the next section, and no deleterious effects on the pellet integrity or speed were observed.

\section{GUIDE TUBE SIMULATION TESTS}

Mockups of the curved guide tubes shown in Fig. 1 were constructed at ORNL, and simulation tests were carried out with 2.7-mm $\mathrm{D}_{2}$ pellets. A pipe gun [2] was used to form and accelerate pellets to speeds of 100 to $1000 \mathrm{~m} / \mathrm{s}$. In previous studies $[5,6]$, it was found that the pellet formation technique (pipe gun vs ice extrusion) was not a significant factor in determining performance parameters. In that same study, the pellet speed limit for the vertical injection simulations was found to be $\approx 400-500 \mathrm{~m} / \mathrm{s}$. Because the HFS lines consist of more bends and some with tighter radii, mockups of both the upper and lower HFS guide tubes were constructed and tested. Photos of pellets at the gun muzzle and guide tube exit (Fig. 3) were taken for each test shot and used to determine 
Test Shot 1947

$10 / 2 / 98$
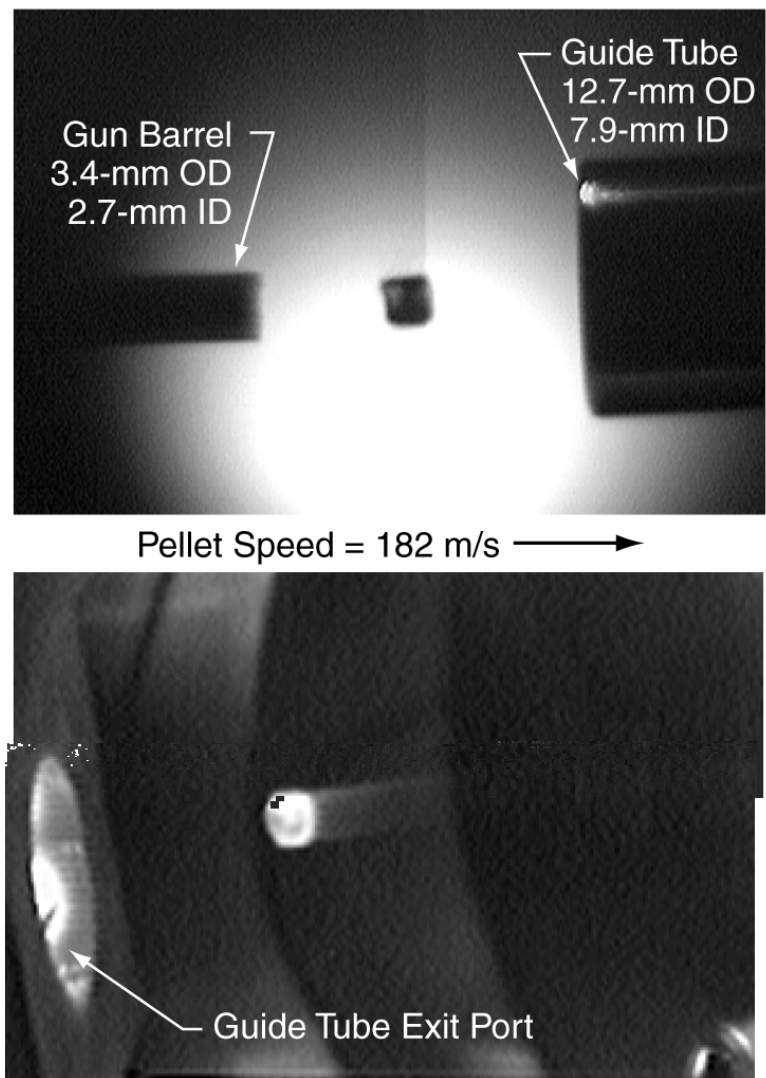

Fig. 3. Photos of $\mathrm{D}_{2}$ pellet at gun muzzle and guide tube exit from simulation test of DIII-D lower HFS pellet injection.

pellet integrity and the speed limit. Data from the lower HFS simulation tests are presented in Fig. 4. The abscissa is the pellet speed for both plots. In the top plot, the ordinate value is the pellet condition at the guide tube exit ( 0 or 1$)$, with 0 signifying broken pellets and 1 intact pellets. The speed transition range in which intact and broken pellets were observed is $\approx 220$ to $300 \mathrm{~m} / \mathrm{s}$. In the bottom plot, the fraction of intact pellets for each speed bracket is illustrated with columns. The data from the upper HFS simulation tests (not included here) had a speed transition range of $\approx 260$ to $300 \mathrm{~m} / \mathrm{s}$. The decreased speed limit for the lower HFS case is expected because the final tube bend of $6.3-\mathrm{cm}$ radius is much tighter than the last bend (23.1-cm radius) for the upper HFS case. This is the only significant difference between the two HFS tube lines. Results from the simulation tests indicate that any pellets with speeds $\leq 200 \mathrm{~m} / \mathrm{s}$ should be delivered intact through the HFS tubes. While the pellet mass loss was not measured in this study, estimates from the photography information suggested $\approx 20 \%$ mass loss through the HFS tubes. Also, the pellet speed measurements indicated that pellets never slow down in the guide tubes by more than a few percent.

\section{OPERATION AND EXPERIMENTS ON DIII-D}

The vertical and HFS pellet injection schemes have been commissioned on DIII-D, including the demonstration of reliable operation and initial experiments. Through the $60^{\circ}(\mathrm{V}+1)$ port,

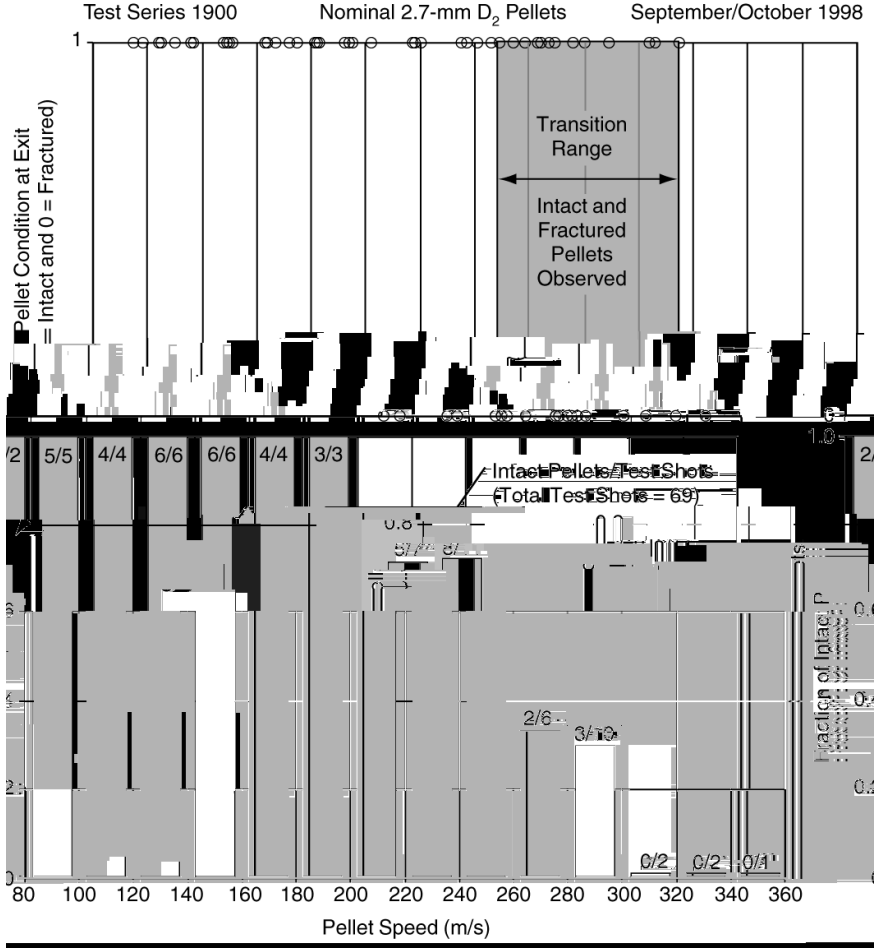

Fig. 4. Results from laboratory simulation of DIII-D lower HFS pellet injection.

210 pellets have been injected during plasma shots. No pellets have been injected through the $0^{\circ}(\mathrm{V}+3)$ port; however, injection via that vertical port is planned for the next experimental run period. From the inner wall, 225 pellets have been injected via the upper HFS tube, and 27 pellets have been injected via the lower HFS tube. Figure 5 includes some experimental data for $2.7-\mathrm{mm} \mathrm{D}_{2}$ pellets injected from different locations (LFS, V+1, and upper HFS) into the same DIII-D plasma shot. The density perturbation is significantly larger for the HFS pellet, even though the pellet speed is much lower than that of the LFS and V+1 pellets. Also, $D_{\alpha}$ in the divertor shows fewer particles leaving the plasma from the

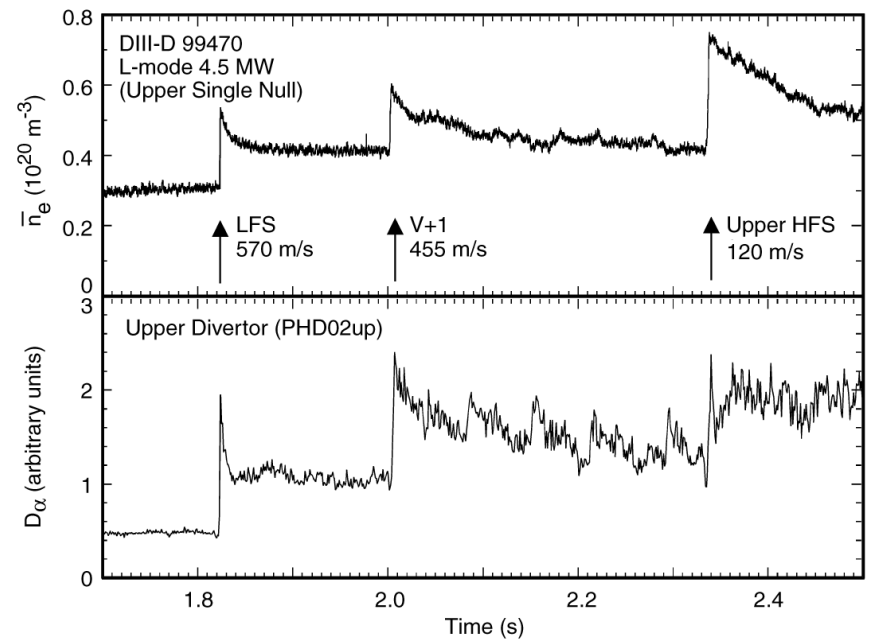

Fig. 5. Electron density evolution and divertor $\mathrm{D}_{\alpha}$ for $2.7-\mathrm{mm} \mathrm{D}_{2}$ pellets injected from different locations into a DIII-D L-mode plasma. 
HFS pellet. The DIII-D experimental results from the new pellet injection schemes have been reported by Baylor et al. $[10,11]$.

\section{SUMMARY}

The DIII-D pellet fueling system now has the unique capability to inject $2.7-\mathrm{mm}$ pellets from three different locations on the same plasma shot; options include (1) standard outside LFS injection (three lines), (2) vertical injection (two lines), and (3) inner wall HFS injection (two lines). The guide tube designs/components allow any tube to be connected to any gun for a given DIII-D experiment A second gun is being modified for slower pellet speeds, and this will add the capability to inject pellets through both HFS tubes on the same plasma shot. This pellet injection system is extremely versatile. Both HFS and vertical pellet injection look promising for plasma fueling, while minimizing the pellet mass loss, and should prove useful tools in future DIIID experiments.

\section{REFERENCES}

[1] S. L. Milora, W. A. Houlberg, L. L. Lengyel, and V. Mertens, "Pellet fueling," Nucl. Fusion 35, 657 (1995).

[2] S. K. Combs, "Pellet injection technology," Rev. Sci. Instrum. 64, 1679 (1993).

[3] P. T. Lang, K. Büchl, M. Kaufmann, R. S. Lang, V. Mertens, H. W. Müller, J. Neuhauser, ASDEX Upgrade Team, and NBI Team,
"High-efficiency plasma refueling by pellet injection from the magnetic high-field side into ASDEX upgrade," Phys. Rev. Lett. 79, 1487 (1997)

[4] J. L. Luxon and L. G. Davis, "Big Dee-A Flexible Facility Operating Near Breakeven Conditions," Fusion Technol. 8, 441 (1985).

[5] S. K. Combs, L. R. Baylor, C. R. Foust, M. J. Gouge, T. C. Jernigan, and S. L. Milora, "Experimental Study of Curved Guide Tubes for Pellet Injection," in Proc. 1997 IEEE/NPSS 17th Symposium Fusion Engineering, San Diego, California, October 6-10, 1997, Vol. 2 (IEEE Cat. No. 97CB36131, Piscataway, N.J., 1998), p. 1102.

[6] S. K. Combs, L. R. Baylor, C. R. Foust, M. J. Gouge, T. C. Jernigan, S. L. Milora, J-F. Artaud, and A. Géraud, "High-Field-Side Pellet Injection Technology," Fusion Technol. 34, 419 (1998).

[7] S. K. Combs, S. L. Milora, L. R. Baylor, C. R. Foust, F. E. Gethers, and D. O. Sparks, "A Three-Barrel Repeating Pneumatic Pellet Injector for Plasma Fueling of the Joint European Torus," J. Vac. Sci. Technol. A6(3), 1901 (1988).

[8] S. K. Combs, T. C. Jernigan, L. R. Baylor, S. L. Milora, C. R. Foust, P. Kupschus, M. Gadeberg, and W. Bailey, "Performance of a Pneumatic Hydrogen-Pellet Injection System on the Joint European Torus," Rev. Sci. Instrum. 60, 2697 (1989).

[9] S. K. Combs, C. R. Foust, and S. L. Milora, "Small-Bore (1.8-mm), High-Firing-Rate (10-Hz) Version of Repeating Pneumatic Hydrogen Pellet Injector," Rev. Sci. Instrum. 66, 2736 (1995).

[10] L. R. Baylor, T. C. Jernigan, and C. Hsieh, "Deposition of Pellets into Tokamak Plasmas," Fusion Technol. 34, 425 (1998).

[11] L. R. Baylor, T. C. Jernigan, S. K. Combs, W. A. Houlberg, P. Gohil, C. Hsieh, and P. Parks, "Pellet Injection into H-mode Plasmas on DIII-D," to be published in 26th Europ. Conf. on Contr. Fusion and Plasma Physics; Europhysics Conf. Abstracts (1999). 